\title{
Therapeutic efficacy of natural prostaglandin in the treatment of pyometra in bitches
}

\author{
Basanti J ena, K. Sadasiva Rao, K. C. S. Reddy and K. B. P. Raghavender
}

College of Veterinary Science,

Sri Venkateshwara Veterinary University, Rajendranagar, Hyderabad, Andhra Pradesh, India

Corresponding author: Basanti Jena, email: drbasantijena@gmail.com

Received: 03-09-2012, Accepted: 10-10-2012, Published online: 25-02-2013

\section{How to cite this article:}

J ena B, Rao KS, Reddy KCS and Raghavender KBP (2013) Therapeutic efficacy of natural prostaglandin in the treatment of pyometra in bitches, Vet. World 6(6):295-299, doi: 10.5455/vetworld.2013.295-299

\begin{abstract}
Aim: The current study was done to study the therapeutic effect of natural prostaglandin in treatment of canine pyometra.

Materials and Methods: Seven bitches were treated with natural $\mathrm{PGF}_{2} \alpha$ i.e. dinoprost tromethamine at the dose rate of 100 $\mu \mathrm{g} / \mathrm{kg}$ body weight subcutaneously once daily for 7 days with supportive therapies. The physiological, haematological and biochemical parameters were studied before $\left(0^{\text {th }}\right.$ day) and after treatment $\left(8^{\text {th }}\right.$ day). Therapeutic efficacy was assessed in terms of return of abnormal parameters to either normal or near normal value as compared to the untreated control group, intensity of side effects and post treatment reproductive status.
\end{abstract}

Results: All physiological, haematological and biochemical parameters in the seven treated bitches returned to normal range at the end of treatment. The intensity of side effects was quite severe in the treatment group. Six bitches came to estrus within 2 months of treatment and out of them four conceived on subsequent mating. In rest three bitches there was recurrence of pyometra within 4 months of treatment.

Conclusion: Though conception rate of recovered bitches is decreased when compared with that of normal healthy bitches still this treatment protocol can be used successfully in treatment of canine pyometra to conserve the breeding capability of bitches.

Keywords: bitch, prostaglandin, pyometra, therapeutic efficacy

\section{I ntroduction}

Pyometra is the accumulation of purulent material occurred within the lumen of the uterus in intact bitches [1] which was reported to induce high mortality in bitches if not treated [2]. It is recognized as one of the main causes of disease and death in the bitch [3]. It is a common disease in countries where routine spaying of young dogs is not common practice [4]. In most cases, the treatment of choice is ovariohysterectomy, but surgery is a radical form of treatment that prevents any further reproduction. In order to conserve the breeding capability of valuable females, medical treatment can be attempted which usually involved the repeated administration of prostaglandins $[5,6]$ which causes lysis of the corpora lutea and a reduction in plasma progesterone concentration. Low progesterone level, further causes relaxation (opening) of the cervix, allow expulsion of the uterine content resulting in reduction in uterine secretions and increased uterine contractions. In addition, prostaglandins have a uterine spasmogenic action which results in the expulsion of uterine fluid. As corpora lutea of bitches are relatively insensitive to the effects of administered prostaglan-

This article is an open access article licensed under the terms of the Creative Commons Attribution License (http://creativecommons. org/licenses/by/2.0) which permits unrestricted use, distribution and reproduction in any medium, provided the work is properly cited. dins, repeated doses are required to cause luteal regression. Administration of prostaglandins caused significant adverse effects including salivation, vomiting, straining, diarrhoea, pyrexia and occasionally respiratory distress [7]. Immediate breeding of the treated bitches during the estrus is recommended to prevent the recurrence [8]. Fertility of recovered bitches is decreased when compared with that of normal, untreated bitches [9].

Though several literatures are available on use of natural prostaglandin in treatment of pyometra but the previous researches depict controversial findings. So the current study was done to study the therapeutic effect of natural prostaglandin in treatment of canine pyometra.

\section{Materials and Methods}

The present work was carried out at Department of Animal Reproduction, Gynaecology and Obstetrics, College of Veterinary Science, Rajendranagar, Hyderabad. Fourteen clinical cases of different breeds in the age group of one to twelve years that were brought to the Animal Reproduction, Gynaecology and Obstetrics Unit, Teaching Veterinary Clinical Complex, Bhoiguda and Campus Hospital, College of Veterinary Science, Rajendranagar, Hyderabad with known breeding history or having clinical symptoms 
Table-1. Physiological, haematological and biochemical parameters

\begin{tabular}{|c|c|c|c|c|c|c|}
\hline \multirow[t]{2}{*}{ Parameters } & \multicolumn{3}{|c|}{ Group I } & \multicolumn{3}{|c|}{ Group II } \\
\hline & $\begin{array}{l}\text { Before treatment } \\
\text { (0th day) }\end{array}$ & $\begin{array}{l}\text { After treatment } \\
\left(8^{\text {th }} \text { day }\right)\end{array}$ & $P$ value & $\begin{array}{l}\text { Before treatment } \\
\text { (0th day) }\end{array}$ & $\begin{array}{l}\text { After treatment } \\
\left(8^{\text {th }} \text { day }\right)\end{array}$ & P value \\
\hline \multicolumn{7}{|l|}{ Physiological parameters } \\
\hline Rectal temperature $\left({ }^{\circ} \mathrm{F}\right)$ & $102.83 \pm 0.28$ & $103.34 \pm 0.18$ & $0.151^{\text {NS }}$ & $103.2 \pm 0.28$ & $102.41 \pm 0.13$ & 0.025 \\
\hline Heart rate (per minute) & $112.00 \pm 4.00$ & $109.86 \pm 2.23$ & $0.648^{\mathrm{NS}}$ & $110.43 \pm 4.07$ & $110.00 \pm 3.08$ & $0.935^{\mathrm{NS}}$ \\
\hline $\begin{array}{l}\text { Respiration rate (per minute) } \\
\text { Haematological parameters }\end{array}$ & $29.57 \pm 1.15$ & $32.00 \pm 0.90$ & $0.122^{\text {NS }}$ & $30.71 \pm 1.32$ & $24.86 \pm 0.88$ & $0.003^{*}$ \\
\hline Haemoglobin (gram \%) & $11.0 \pm 0.32$ & $10.70 \pm 0.29$ & $0.487^{\mathrm{NS}}$ & $11.08 \pm 0.38$ & $12.40 \pm 0.25$ & 0.014 \\
\hline PCV $(\%)$ & $33.83 \pm 0.92$ & $33.30 \pm 0.90$ & $0.690^{\mathrm{NS}}$ & $34.07 \pm 1.06$ & $37.67 \pm 0.89$ & 0.024 \\
\hline TEC $\left(\times 10^{6} / \mu \mathrm{l}\right)$ & $5.48 \pm 0.17$ & $5.33 \pm 0.14$ & $0.488^{N S}$ & $5.54 \pm 0.89$ & $6.17 \pm 0.14$ & $0.017^{*}$ \\
\hline $\mathrm{MCV}(\mathrm{fl})$ & $66.88 \pm 0.52$ & $66.77 \pm 0.51$ & $0.878^{\mathrm{NS}}$ & $66.30 \pm 0.63$ & $67.37 \pm 0.42$ & $0.184^{\mathrm{NS}}$ \\
\hline $\mathrm{MCH}(p g)$ & $21.44 \pm 0.32$ & $21.14 \pm 0.31$ & $0.517^{\mathrm{NS}}$ & $21.91 \pm 0.48$ & $22.16 \pm 0.45$ & $0.719^{\mathrm{NS}}$ \\
\hline $\operatorname{MCHC}(\%)$ & $31.48 \pm 0.27$ & $31.28 \pm 0.27$ & $0.614^{\mathrm{NS}}$ & $31.34 \pm 0.40$ & $31.48 \pm 0.40$ & $0.806^{\mathrm{NS}}$ \\
\hline $\operatorname{TLC}\left(\times 10^{3} / \mu \mathrm{l}\right)$ & $33.27 \pm 7.74$ & $34.14 \pm 7.76$ & $0.938^{\text {NS }}$ & $33.44 \pm 6.89$ & $14.16 \pm 2.76$ & 0.016 \\
\hline Neutrophil (\%) & $76.86 \pm 1.06$ & $78.00 \pm 0.97$ & $0.442^{N S}$ & $79.00 \pm 0.62$ & $69.43 \pm 0.78$ & 0.000 \\
\hline Lymphocyte (\%) & $11.14 \pm 0.94$ & $10.00 \pm 0.92$ & $0.403^{\mathrm{NS}}$ & $9.71 \pm 0.52$ & $21.57 \pm 0.78$ & $0.000^{*}$ \\
\hline Monocyte (\%) & $9.86 \pm 0.51$ & $10.28 \pm 0.52$ & $0.567^{\mathrm{NS}}$ & $9.00 \pm 0.49$ & $7.14 \pm 0.40$ & $0.013^{*}$ \\
\hline Eosinophil (\%) & $2.14 \pm 0.40$ & $1.71 \pm 0.28$ & $0.403^{\mathrm{NS}}$ & $2.28 \pm 0.18$ & $1.86 \pm 0.26$ & $0.205^{\mathrm{NS}}$ \\
\hline \multicolumn{7}{|l|}{ Biochemical parameters } \\
\hline $\mathrm{BUN}(\mathrm{mg} / \mathrm{dL})$ & $26.28 \pm 1.47$ & $29.85 \pm 1.18$ & $0.083^{\mathrm{NS}}$ & $23.43 \pm 1.17$ & $19.71 \pm 0.64$ & $0.017^{\star}$ \\
\hline Creatinine (mg/dL) & $2.10 \pm 0.08$ & $2.18 \pm 0.06$ & $0.423^{\mathrm{NS}}$ & $2.14 \pm 0.07$ & $1.84 \pm 0.03$ & $0.003^{*}$ \\
\hline AST (U/L) & $49.14 \pm 1.24$ & $50.86 \pm 1.20$ & $0.341^{\mathrm{NS}}$ & $49.00 \pm 1.23$ & $42.71 \pm 1.15$ & $0.003^{*}$ \\
\hline $\operatorname{ALT}(\mathrm{U} / \mathrm{L})$ & $28.28 \pm 2.09$ & $24.28 \pm 1.49$ & $0.145^{\mathrm{NS}}$ & $26.00 \pm 2.72$ & $33.71 \pm 1.89$ & $0.039^{*}$ \\
\hline ALP (U/L) & $153.43 \pm 5.83$ & $158.71 \pm 5.33$ & $0.516^{\mathrm{NS}}$ & $156.57 \pm 7.65$ & $135.14 \pm 4.26$ & $0.031^{*}$ \\
\hline $\mathrm{TP}(\mathrm{g} / \mathrm{dL})$ & $7.94 \pm 0.27$ & $8.13 \pm 0.24$ & $0.619^{\mathrm{NS}}$ & $8.01 \pm 0.34$ & $7.21 \pm 0.12$ & 0.046 \\
\hline Albumin (g/dL) & $2.91 \pm 0.09$ & $2.93 \pm 0.11$ & $0.923^{\mathrm{NS}}$ & $2.98 \pm 0.26$ & $3.21 \pm 0.03$ & $0.401^{\mathrm{NS}}$ \\
\hline Globulin (g/dL) & $5.03 \pm 0.27$ & $5.20 \pm 0.27$ & $0.665^{\mathrm{NS}}$ & $5.03 \pm 0.27$ & $4.00 \pm 0.11$ & $0.000^{*}$ \\
\hline Total Bilirubin (mg/dL) & $0.46 \pm 0.06$ & $0.48 \pm 0.07$ & $0.758^{\mathrm{NS}}$ & $0.47 \pm 0.08$ & $0.43 \pm 0.04$ & $0.646^{\mathrm{NS}}$ \\
\hline
\end{tabular}

NS; - Not significant, *; - Significant $(P<0.05)$, **; - Significant $(P<0.01)$

suspected for open type of pyometra which was further confirmed by using diagnostic methods like abdominal palpation, radiography and ultrasound examination were taken for the study. Bitches were divided into two groups each consisting of seven bitches and subjected to different treatment protocols. Group I bitches were treated only with supportive therapies (control group). Bitches in Group II, were treated with natural $\mathrm{PGF}_{2} \alpha$ i.e. dinoprost tromethamine at the dose rate of 100 $\mu \mathrm{g} / \mathrm{kg}$ body weight subcutaneously once daily for 7 days with supportive therapies. The physiological, haematological and biochemical parameters were studied before $\left(0^{\text {th }}\right.$ day $)$ and after treatment $\left(8^{\text {th }}\right.$ day $)$. Attempts were made to contact the owners of the bitches that recovered after various treatments to obtain the follow up data. All the data pertaining to post treatment return to estrus, breeding, conception and recurrence were made. Therapeutic efficacy was assessed in terms of return of abnormal parameters to either normal or near normal value as compared to the untreated control group, intensity of side effects and post treatment reproductive status. All bitches of control group and recurred bitches had undergone ovariohysterectomy. The results of the study were recorded and statistically analyzed as per the methods suggested by Snedecor and Cochran [10].

Analysis of variance was done to find out the significant difference between the physiological, haematological and biochemical parameters before and after treatment in different groups.

\section{Results}

Treatment response: All the seven bitches were successfully treated by using natural $\mathrm{PGF}_{2} \alpha$ (Dinoprost tromethamine) at the dose rate of $100 \mu \mathrm{g} / \mathrm{kg}$ body weight once daily for 7 days subcutaneously along with supportive therapy (100 per cent recovery rate) which resulted in disappearance of externally visible clinical signs of pyometra. Bitches became active and alert by $8^{\text {th }}$ day of treatment. There was total ceasation of vaginal discharge with little or no palpable evidence of enlargement of uterus which was confirmed by abdominal radiography and ultrasonography. Normal rectal temperature, respiration rate with an improved appetite were observed at end of treatment that is presented in Table- 1 . The recovery rate was 100 per cent in the treated group.

There was significant increase in mean haemoglobin, packed cell volume and total erythrocyte count level $(P<0.05)$ indicating resolution of anaemia on day 8 as compared to control group bitches. There was significant decrease in mean total leucocyte count $(P<0.05)$, neutrophil count and monocyte count level $(P<0.01)$ with increase in lymphocyte count as compared to control group bitches resulting in normal blood picture in all the treated bitches on $8^{\text {th }}$ day of observation which is reported in Table-1.

There was significant decrease in blood urea nitrogen $(P<0.05)$, creatinine $(P<0.01)$, aspartate transaminase $(P<0.01)$, alkaline phosphatase $(P<$ $0.05)$, mean total protein $(P<0.05)$ and globulin level in serum $(P<0.01)$ on $8^{\text {th }}$ day of observation as compared to control group bitches. There was significant increase in mean alanine transaminase level $(P<0.05)$ as compared to control group bitches resulting in normal serum biochemistry in all the treated bitches on $8^{\text {th }}$ day of observation which is represented in Table-1. Other physiological, haematological and biochemical parameters did not show any significant change following treatment with $\mathrm{PGF}_{2} \alpha$ as compared to control 
group bitches. All data pertaining to physiological, haematological and biochemical parameters of control group and treatment group has been represented in the Table-1.

Side effects: In this present study several physical reactions were observed in group II bitches which were subjected to natural $\mathrm{PGF}_{2} \alpha$ (Dinoprost tromethamine) at the dose rate of $100 \mu \mathrm{g} / \mathrm{kg}$ body weight subcutaneously. The side effects observed were vomition $(6 / 7$, $85.71 \%)$, panting $(6 / 7,85.71 \%)$, restlessness (7/7, $100 \%)$, hyperpnoea $(7 / 7,100 \%)$, defaecation $(5 / 7$, $71.43 \%)$ and urination $(5 / 7,71.43 \%)$. The reactions started within few minutes after $\mathrm{PGF}_{2} \alpha$ administration and disappeared within 1 to 1.5 hours.

Recurrence: Though complete clinical recovery was observed in all the bitches after treatment, in three bitches there was recurrence of pyometra within 4 months of treatment. Out of the three bitches, one recurred within one month of treatment. Recurrence rate was 42.85 per cent in this group of bitches.

In all the recurred bitches there was presence of all classical clinical signs of pyometra like vaginal discharge, polydipsia, polyuria, lethargy and anorexia. All physiological, haematological and biochemical parameters shifted towards an abnormal level simulating to the condition observed just before treatment. Abdominal palpation revealed palpable uterus which was further confirmed by radiography or ultrasonography revealing accumulation of purulent exudates in uterus.

Post treatment reproductive status: After complete clinical recovery of all the bitches in dinoprost tromethamine treated group, six bitches $(85.71 \%)$ came to estrus within 2 months of treatment which were subsequently mated. Out of them four bitches conceived as confirmed by ultrasonography resulting in 57.15 per cent conception rate in the treated group.

\section{Discussion}

All the animals in the treated group recovered after completion of treatment protocol which is similar to the previous findings [11-13]. However, 48.57 per cent recovery rate was reported by using Dinoprost tromethamine for treatment of canine pyometra in some study [14]. Natural prostaglandin is preferable to prostaglandin analogues, as it not only induced substantial luteolysis, but also resulted in more substantial uterine contractions [15]. There was significant change in haematological parameters in the treatment group as compared to control group bitches resulting in normal blood picture in all the treated bitches on $8^{\text {th }}$ day of observation. These findings were in accordance with the previous reports $[5,11,14]$. There was significant change in biochemical parameters in the treatment group as compared to control group bitches resulting in normal serum biochemistry in all the treated bitches on $8^{\text {th }}$ day of observation. These findings were in agreement with the previous reports of treatment of pyometra using natural $\mathrm{PGF}_{2} \alpha$ for at the dose rate of $250 \mu \mathrm{g} / \mathrm{kg} /$ day for 5 days [16].

All the above effects might be due to effect of $\mathrm{PGF}_{2} \alpha$ exerted on uterine myometrium, cervix and corpora lutea. $\mathrm{PGF}_{2} \alpha$ stimulated uterine motility. This myotonic effect increased intrauterine pressure to cause movement of uterine contents towards the cervix. The contractile effect of $\mathrm{PGF}_{2} \alpha$ on myometrium, gastrointestinal tract, tracheobronchial and bladder smooth musculature accounts for the clinical responses observed and reflects the physiologic effects of endogenous prostaglandins [13]. $\mathrm{PGF}_{2} \alpha$ offers the advantage of a double action i.e. myocntractile and luteolytic [17]. Clinical recovery after treatment with natural $\mathrm{PGF}_{2} \alpha$ might be due to its effect on uterine myometrium, cervix and corpra lutea. It caused contraction of myometrium and relaxation of cervix which resulted in expulsion of the exudates from the uterus. Lysis of the corpora lutea (or) transitory inhibition of luteal steroidogenesis also resulted from administration of $\mathrm{PGF}_{2} \mathrm{\alpha}$. These actions were particularly dependent on the dosage, route and frequency of administration and timing of $\mathrm{PGF}_{2} \alpha$ therapy within the luteal phase. The resultant decreased plasma progesterone concentration reduced the stimulus for endometrial growth and glandular secretions resulting in resolving the vaginal discharge and other clinical signs [8].

The intensity of side effects were quite severe in treatment group which might be due to higher dose of natural $\mathrm{PGF}_{2} \alpha$ (Dinoprost tromethamine) used for the treatment $[8,13,18,19]$. Side effects were dosedependent [17] and were known to diminish with repetition of treatment [15]. Though all the above authors had reported salivation as the most common side effect observed after $\mathrm{PGF}_{2} \alpha$ therapy, in the present study it was not observed might be due to the administration of Atropine sulphate 10-15 minutes prior to administration of $\mathrm{PGF}_{2} \alpha$ [20]. Attempts were made to minimise the side effects by withholding food and water supplied to the bitches 4-6 hours prior to administration of $\mathrm{PGF}_{2} \alpha$, use of Atropine sulphate and providing mild walk to bitches after $\mathrm{PGF}_{2} \alpha$ injection in order to facilitate early metabolism and excretion of $\mathrm{PGF}_{2} \alpha$ end product $[5,21]$. However, use of natural $\mathrm{PGF}_{2} \alpha$ at a dose of $20 \mu \mathrm{g} / \mathrm{kg}$ body weight [11] and 30 $\mu \mathrm{g} / \mathrm{kg}$ body weight [12] in repeated doses daily for treatment of canine pyometra showed no adverse side effects which might be due to the lower dose used.

In the present study recurrence rate was in accordance with the previous reports of 40 per cent [5]. At the time of relapse of the disease there were again the typically raised AST, decreased ALT and increased AST/ALT [16]. However, in contrary to the present report, it has been reported that there was no recurrence of pyometra within 10 months [11], 12 months [14] and 
6 months [18] of observation period. Immediate breeding of the treated bitches during the estrus is recommended to prevent the recurrence [8]. Prostaglandin treatment did not eliminate the disease, but only reduced it to a subclinical level. Deep-seated infection could remain until next diestrus, when the plasma progesterone concentration became high as in pregnancy. Uterine defence mechanisms were inhibited by progesterone during diestrus in the bitches so that infection could become clinically apparent at this time. Hence recurrences were most common during diestrus. As long term recurrence rate was high, prostaglandin treatment was not recommended for bitches where pregnancy was undesirable or improbable. In such bitches it might be useful only in temporarily decreasing severity of clinical signs. In bitches with a favourable short-term response to treatment it would seem too prudent to breed at first post treatment estrus. Since pyometra might recur as late as 27 months after treatment, it was unlikely that postponement of breeding would be more successful [5]. Though several authors had reported use of second series of $\mathrm{PGF}_{2} \alpha$ therapy in the bitches affected with pyometra $[13,22]$, but in the present study it was not practised due to owners' concern. All the recurred bitches had undergone ovariohysterectomy.

The conception rate in the present study was in accordance with the previous finding where it has been reported that expected conception rate varied from 50-65 per cent depending on the age of the animal, with fertility generally being highest in younger animals [19]. After breeding all the bitches in first estrus after treatment with dinoprost tromethamine, four out of the 10 bitches (40\%) reproduced within one year [5]. However, it has also been reported that the conception rate of the bitches in which estrus had returned was 83.3 per cent [14] which was higher than the report of the present study.

\section{Conclusion}

All the seven bitches were successfully treated by using natural $\mathrm{PGF}_{2} \alpha$ (Dinoprost tromethamine) at the dose rate of $100 \mu \mathrm{g} / \mathrm{kg}$ body weight once daily for 7 days subcutaneously along with supportive therapy with all physiological, haematological and biochemical parameters returning to normal range. This was further confirmed by using ultrasonography which revealed uterus either invisible or difficult to visualise. The intensity of side effects were quite severe might be due to higher dose of natural $\mathrm{PGF}_{2} \alpha$ (Dinoprost tromethamine) used for the treatment. Three bitches showed recurrence of pyometra within 4 months of treatment. As conception rate was at optimum level this protocol can be successfully tried in treatment of canine pyometra where the breeding capability of the animal is desired to be conserved.

\section{Authors' contribution}

This article is the part of MVSc research work of the first author. All authors contributed equally in the whole research work as well as in the preparation of manuscript. All authors read and approved the final manuscript.

\section{Acknowledgements}

The authors are thankful to Sri Venkateswara Veterinary University, Tirupati for giving an opportunity to do the research. We wish to extend our thanks to the Dean, College of Veterinary Science, Rajendranagar, Hyderabad for providing all the facilities to complete the research successfully.

\section{Competing interests}

Authors declare that they have no competing interest.

\section{References}

1. Pretzer S. D. (2008) Clinical presentation of canine pyometra and mucometra: A review, Theriogenology, 70 : 359-363.

2. Singh K. P., Singh B., Singh J. P., Singh S. V., Singh P. and Singh H. N. (2010) Diagnostic and therapeutic management of pyometra in bitches, Intas Polivet, $11: 86$ 87.

3. Coggan J. A., Melville P. A., Oliveira C. M., Faustino M., Moreno A. M. and Benites N. R. (2008) Microbiological and histopathological aspects of canine pyometra, Brazilian Journal of Microbiology, 39: 477-483.

4. Pelander L., Hagman R. and Häggström J. (2008) Concentrations of cardiac Troponin I before and after ovariohysterectomy in 46 female dogs with pyometra, Acta Veterinaria Scandinavica, 50:35.

5. Meyers-Wallen V. N., Goldschmidt M. H. and Flickinger G. L. (1986) Prostaglandin $\mathrm{F}_{2} \alpha$ treatment of canine pyometra, Journal of American Veterinary Medical Association, 189 : $1557-1561$.

6. Renton J. P., Boyd J. S. and Harvey M. J. A. (1993) Observations on the treatment and diagnosis of open pyometra in the bitch (Canis familiaris), Journal of Reproduction and Fertility Supplement, 47 :465-469.

7. Hubler M., Arnold S., Casal M., Fluckiger M., Hauser B., Corboz L. and Rusch P. (1991) Use of a low dose prostaglandin $\mathrm{F}_{2}$ alpha in bitches, Schweizer Archiv für Tierheilkunde, 133:323-329 (Abst).

8. Nelson R. W., Feldman E. C. and Stabenfeldt G. H. (1982) Treatment of canine pyometra and endometritis with prostaglandin $\mathrm{F}_{2} \alpha$, Journal of American Veterinary Medical Association, $181: 889-903$.

9. Gobello C., Castex G., Klima L., Rodriguez R. and Corrada Y. (2003) A study of two protocols combining aglepristone and cloprostenol to treat open cervix pyometra in the bitch, Theriogenology, 60:901-908.

10. Snedecor G. W. and Cochran W. G. (1994) Statistical Methods. $8^{\text {th }}$ Edn. Iowa State University Press, USA.

11. Arnold S., Hubler M., Casal M., Fairburn A., Baumann D., Flueckiger M. and Ruesch P. (1988) Use of low dose prostaglandin for treatment of canine pyometra, Journal of Small Animal Practice, 29:303-308.

12. Sridevi P., Balasubramanian S., Devanathan T. G. and Pattabiraman S. R. (2000) Low dose prostaglandin $\mathrm{F}_{2}$ alpha therapy in treatment of canine pyometra, Indian Vet. J, 77 : 889-890.

13. Pande N., Prabhakar S., Gandotra V. K., Nanda A. S. and Singla V. K. (2004) Comparative efficacy of parenteral and intravaginal administration of $\mathrm{PGF}_{2} \alpha$ for treatment of pyometra in bitches, Indian Journal of Animal Reproduction, $25: 17-18$.

14. Tsumagari S., Ishinazaka T., Kamata H., Ohba S., Tanaka S., Ishii M. and Memon M. A. (2005) Induction of canine 
pyometra by inoculation of Escherichia coli into the uterus and its relationship to reproductive features, Animal Reproduction Science, 87 : 301-308.

15. Verstegen J., Dhaliwal G., Onclin K. V. (2008) Mucometra, cystic endometrial hyperplasia, and pyometra in the bitch: Advances in treatment and assessment of future reproductive success, Theriogenology, 70:364-374.

16. Schepper J. D., Stock J. V. D. and Capiau E. (1987) The characteristic pattern of Aspartate Amino Transferase and Alanine Amino Transferase in the bitch with the cystic hyperplasia pyometra Complex: effect of medical or surgical treatment, Veterinary research communications, 11:65-75.

17. Romagnoli S. (2008) Reproduction: How I treat pyometra, Proceedings of the Southern European Veterinary Congress and Congreso Naciona AVEPA, Barcelona, Spain.

18. Pawde A. M. and Kumar H. (1996) Medical management of canine pyometra complex, Indian Vet. J., 73:197-198.

19. Smith F. O. (2006) Canine pyometra, Theriogenology, 66 : 610-612.

20. Lein D. H., Concannon P. W., Hornbuckle W. E., Gilbert R. A., Glendening J. R. and Dunlap H. L. (1989) Termination of pregnancy in bitches by administration of Prostaglandin F2 $\alpha$, Journal of Reproduction and Fertility Supplement, 39 : 231-240.

21. Reddy K. R. C., Rao K. S., Raju K. G. S., Raghavender K. B. P. and Reddy A. G. (2010) Therapeutic efficacy of Mifepristone, cabergoline and cloprostenol for termination of pregnanacy in bitches, Indian Journal of Animal Reproduction, $31: 19-22$.

22. Feldman E. C. and Nelson R. W. (1996) Cystic Endometrial Hyperplasia and Pyometra Complex, Canine and Feline Endocrinology and Reproduction, $2^{\text {nd }}$ Edn. pp. 605-618.

$* * * * * * * *$ 